\title{
Motivation and Second Language Acquisition ${ }^{1}$
}

\author{
R.C. GARDNER \\ University of Western Ontario
}

Received: 26-1-07 / Accepted version: 10-02-07

ISBN: $1697-7467$

\begin{abstract}
This paper posits four stages of language acquisition, identified as elemental, consolidation, conscious expression, and automaticity and thought, and considers the role of motivation in this process. It distinguishes between two types of motivation, language learning motivation and classroom motivation, indicating how these relate to two distinct contexts, the cultural and the educational through their influence on integrativeness and attitudes toward the learning situation. It discusses how the two types of motivation are differentially involved in the four stages, and empirical support for this perspective is presented in the form of path analyses of two samples of students from Catalonia.
\end{abstract}

Key words: motivation, second language acquisition.

RESUMEN: En este trabajo se establecen cuatro etapas en el proceso de adquisición de las lenguas, identificadas como etapa elemental, de consolidación, expresión consciente, automática y de pensamiento, y se considera el rol de la motivación en este proceso. Se distinguen dos tipos de motivación, motivación en el aprendizaje de la lengua y motivación de aula, y se indica cómo ambas se relacionan con dos tipos de contextos diferentes, el contexto cultural y el educativo a través de su influencia en los procesos de integración y en las actitudes hacia la situación de aprendizaje. Se demuestra cómo los dos tipos de motivación están implicados de forma diferenciada en las cuatro etapas y se presenta un estudio empírico que estudia la relación entre una serie de variables referidas a dos muestras de estudiante de ESO de Cataluña.

Palabras clave: motivación, adquisición de una segunda lengua.

I have been asked on occasion why I think there must be some sort of motivation to learn a second language, because most people learn at least one language, and often children from a bilingual home learn two languages, apparently with ease. Moreover, these people speak the language, they understand the language, and often they both read and write it, so why should motivation be important. My answer is that generally language is an integral part of growing up (which provides motivation in its own right), and is necessary to communicate

${ }^{1}$ This manuscript was the basis of an address by the author to the Seminario Sobre Plurilingüismo: Las Aportaciones Del Centro Europeo de Lenguas Modernas de Graz, on December 15, 2006 at the Universidad de Alcalá, Spain. Preparation of the manuscript was facilitated by a grant (410-2002-0810) from the Social Sciences and Humanities Research Council of Canada. I would like to express my appreciation to Dr. M. Bernaus, Universitat Autònomia de Barcelona for her collaboration on the research reported and to Dan Koff for his assistance in preparing this manuscript. 
and participate in ones environment. Often, this is not the case for second languages, especially those "learned" in school. There are many advantages for knowing other languages but they are not absolutely necessary, and as a consequence, motivation (as well as ability) can play an important role in learning a second language. And there are many things that can affect this motivation. I hope today to convince you of the importance of motivation in second language acquisition and to demonstrate that it is more complex than merely wanting to learn the language.

Our research for the past 45 years has been concerned with the role of attitudes and motivation in second language acquisition, and during this time we have obtained a considerable amount of data and have developed a model linking attitudes and motivation to achievement in the second language as well as to a host of other behaviours that relate to language learning and retention. Rather than review a number of our studies and present a bunch of statistics today, I would like to focus on the role of motivation and language learning in general and discuss the implications of our research to language teaching and pedagogy. In this vein, I intend to direct my attention to the following four points:
a. Two motivational constructs
b. Stages of language acquisition
c. Cultural and educational contexts
d. Results from Spain

It is my view that these points are central to understanding a student's general level of motivation to learn a second language as well as the specific motivation that exists in any language class or other language learning situation. I begin by making the obvious observation that motivation is a very complex phenomenon with many facets. In fact, in 1981, Kleinginna and Kleinginna presented 102 statements about the construct. It really isn't possible to give a simple definition of motivation, though one can list many characteristics of the motivated individual. For example, the motivated individual is goal directed, expends effort, is persistent, is attentive, has desires (wants), exhibits positive affect, is aroused, has expectancies, demonstrates self-confidence (self-efficacy), and has reasons (motives).

As you can see some of these characteristics are cognitive in nature, some are affective, and some are behavioural. Motivation to learn a second language is not a simple construct. It cannot be measured by one scale; perhaps the whole range of motivation cannot be assessed by even three or four scales. It definitely cannot be assessed by merely asking individuals to give reasons for why they think learning a language is important to them.

\section{Two motivational CONSTRUCTS}

When considering motivation and second language learning or acquisition, it is possible to consider two types of motivational constructs. Our research has always contended that there are in essence two types of motivation that should be considered when referring to second language acquisition, and I am not referring here to the integrative-instrumental dichotomy (or even the intrinsic-extrinsic one) that is often discussed in the research literature. I refer instead to the distinction between language learning motivation and classroom learning motivation. 
By language learning motivation, I mean the motivation to learn (and acquire) a second language. This type of motivation is considered in the socio-educational model of second language acquisition (Gardner, 1985), the social context model (Clément, 1980), the Selfdetermination model (Noels, \& Clément, 1996), the Willingness to Communicate model (MacIntyre, Clément, Dörnyei, \& Noels, 1998), and the extended motivational framework (Dörnyei, 1994) to name a few. It is a general form of motivation relevant in any second language-learning context. It is not a trait, as some individuals contend, but it is a general characteristic of the individual that applies to any opportunity to learn the language. It is relatively stable, because of its presumed antecedents, but it is amenable to change under certain conditions. The various models referred to above all agree that it as an attribute with significant implications for the individual; they differ in terms of its antecedents and/or correlates, as well as in how it might be assessed.

The second class of motivation is classroom learning motivation, specifically the language classroom. This is the type of motivation emphasized by Heckhausen and Kuhl (1985); it is the type characterized by Dörnyei's tripartite pre-actional, actional and post-actional motivation, and is common to educational psychology in general. It is also represented in the socioeducational model of second language acquisition, though it is considered an integral part of motivation in general (Gardner, 1985). It refers to the motivation in the classroom situation, or in any specific situation. The focus is on the individuals' perception of the task at hand, and is largely state oriented. Obviously, it will be influenced by a host of factors associated with the language class. Thus, it is clear that the teacher, the class atmosphere, the course content, materials and facilities, as well as personal characteristics of the student (such as studiousness, etc.,) will have an influence on the individual's classroom learning motivation. In the socio-educational model, we contend that it will also be influenced by the general language learning motivation referred to above. Of course, in a very real sense, one cannot distinguish between the two types of motivation. They operate on the individual at any given time, but it is meaningful to consider that both of them are operative.

Just as it is difficult to propose a simple definition of motivation, it is also difficult to provide a simple definition of what it means to learn a second language. In his seminal research on bilingual development, W. E. Lambert $(1955 ; 1956 a, b, c)$ identified what he referred to as two clusters in the process of becoming bilingual, the Vocabulary cluster and the Cultural cluster. In his research, he contrasted the language behaviour of three groups of individuals in his study conducted in the USA. One group was comprised of 14 Undergraduates majoring in French, another consisted of 14 graduate students majoring in French, and the third was a group of 14 native French speaking individuals who had lived for at least 7 years in the USA and who used English on a daily basis.

He compared the three groups on a number of measures of French proficiency and French-English bilinguality involving word association and reaction time measures, and found as expected that performance improved from the undergraduates to the graduates to the French native speakers. On some measures, however, there were no significant differences among the groups; on others there were no significant differences between the undergraduate and graduate students, while on other measures, the graduate students were significantly better than the undergraduates but significantly inferior to the native French speakers. On the basis of these results, he proposed that there was a distinct pattern in the growth of proficiency and bilingual skills due to experience in the other language. He concluded that there were a series of barriers to overcome in the process of language acquisition. He identified 
one as a vocabulary cluster, by which he meant the elements of the language, not simply individual vocabulary items. This he felt was a relatively easy stage to master. Another, and much more difficult one, he identified as the cultural cluster. He claimed that to overcome this barrier it was necessary for the individual to make the language part of the self. He also hypothesized that there may be other phases an individual must master in the process of learning a language.

\section{Stages in language acQuisition}

In our model of second language acquisition and development, we hypothesize that there are at least four stages that can be identified, and they are comparable to those involved in the development of one's first language. Figure 1 presents a schematic representation of these stages.

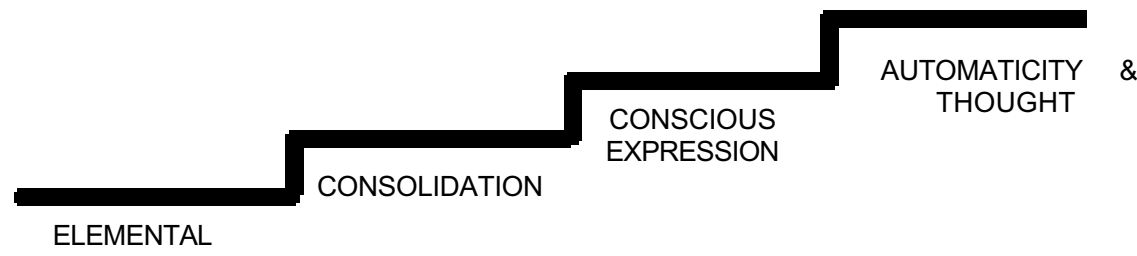

The initial stage is Elemental. In this stage the individual is learning the basics of the language, vocabulary, grammar, pronunciations, etc. (what Lambert would term the vocabulary cluster). We see this in the development of one's first language when the toddler learns new words, begins to put words together, mispronounces some words but corrects them later, etc... With the second language student, we see the same process when initial vocabulary is learned, equivalents with the first language are recognized, simple declarative sentences are memorized, etc. The second stage is Consolidation, where the elements of the language are brought together and some degree of familiarity with the language is achieved. We see this stage in the young child learning the first language, when they begin to recognize that language is a system where some elements are correct and others incorrect, and they develop rules for pluralization, sentence structure, and the understanding of idioms, etc. A similar pattern occurs for students learning a second language, when they find that some of the structures and elements can be like those in their native language while others can be very different, when they learn that some expressions are meaningful, others not, etc. In the third stage, there is Conscious Expression, during which the individual can use the language but with a great deal of conscious effort. The individual can communicate thoughts and ideas, but there is a lot of deliberation about what is being expressed. For the young first language learner, this phase can be recognized by the use of a lot of speech hesitations such as um, er, uh, where the individual is actively searching for the right words or form of expression. For the learner of a second language, you can observe the same phenomenon, and often get the impression 
that the individual is in fact searching the first language for help in knowing how to express the idea in the second language. The fourth stage is identified as Automaticity and Thought to indicate that at the ultimate stage language and thought merge and language becomes automatic in most contexts. This could well correspond to Lambert's cultural cluster. In this phase, language and self become interconnected. One no longer thinks about the language, but thinks in the language.

This analysis is not meant to be definitive as to the stages of language acquisition, but it does serve to highlight what is meant by "learning" the language, and to emphasize that it has different meanings at different stages of the learning process. It is similar to Krashen's (1988) distinction between second and/or foreign language learning versus acquisition, in that it emphasizes that language learning refers to the development of knowledge and skill that permits varying degrees of communication with others, while acquisition involves making the language part of the self. It is with this general view where the concept of motivation becomes important, and the distinction between language learning motivation and classroom learning motivation becomes paramount.

Given that there are various stages of language development one can well ask what we mean by language learning. Learning vocabulary is language learning. Learning structure, pronunciation, etc., is language learning. Learning to communicate in the language is language learning. Even passing into the stage of automaticity and thought can be considered language learning, though Krashen might favour the term acquisition at this stage. That is, at different ages and stages, learning the language can mean different things. In our research we have investigated different aspects of second language learning varying from simple vocabulary learning (in a laboratory setting) to the fluent use of the language in oral communication. We have defined achievement in terms of performance on objective tests of grammar and aural comprehension, written production, reading comprehension, oral production, grades in the language course, etc., and what amazes me is that motivation has been found to be implicated at all stages.

\section{Cultural and educational contexts}

When discussing the roots of motivation to learn a second language in the school context we have proposed that we should consider it from the point of view of both the Educational Context (as we would for any school subject) and the Cultural Context (which is generally not that relevant to most school subjects). That is, studying a second language is unlike studying most other subjects in that it involves taking on elements of another culture (i.e., vocabulary, pronunciations, language structure, etc.,), while most other school subjects involve elements common to one's own culture. By saying that this should be considered when focussing on the concept of motivation, we mean that the individual is a member of a particular culture and many features of the individual are influenced by that culture. In the individual, this cultural context is expressed in terms of ones attitudes, beliefs, personality characteristics, ideals, expectations, etc. With respect to language learning, therefore, the individual will have various attitudes that might apply to language learning, beliefs about its value, meaningfulness, and implications, expectations about what can and cannot be achieved, 
and the importance of various personality characteristics in the learning process. All of these characteristics originate and develop in the overall cultural context as well as the immediate family. In North America, it is generally accepted that Europeans are better at learning languages than North Americans, and whether or not this is true, it can influence the North American's beliefs about his/her own success. Hence, we hypothesize that the cultural context can have an effect on the individual's ultimate success in learning the language. A general overview of the model is presented in Figure 2.

Figure 2: A Model Indicating the Effects of the Cultural and Educational Contexts on Motivation in Second Language Learning

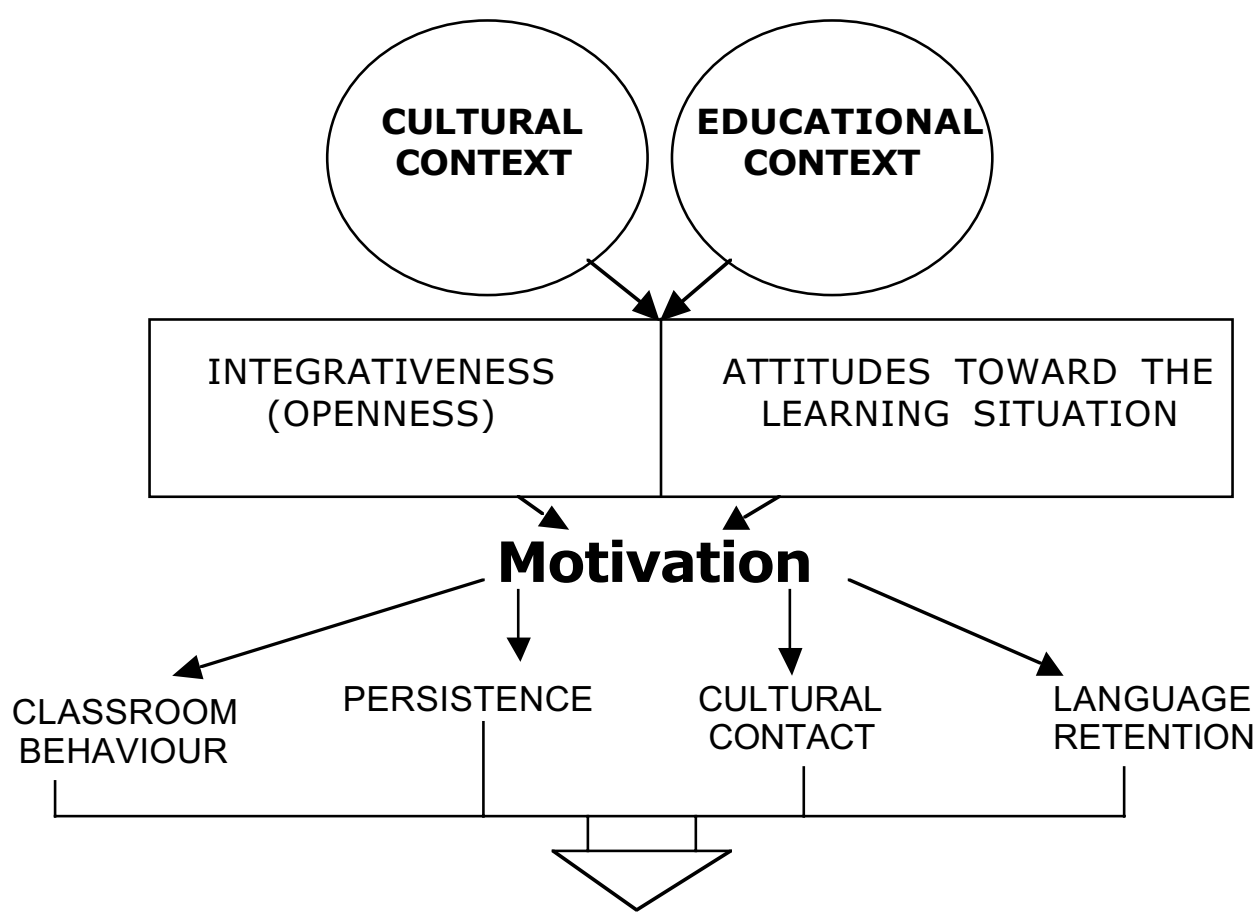

LANGUAGE ACHIEVEMENT AND USE

The Educational Context is important too, of course, and for most subjects it will play a role in the motivation of the student. Other variables might be relevant, but generally they will be relatively less important and largely idiosyncratic. The educational context refers generally to the educational system in which the student is registered, and specifically to the immediate classroom situation. When considering the educational context, we focus on the expectations of the system, the quality of the program, the interest, enthusiasm, and skills of the teacher, the adequacy of the materials, the curriculum, the class atmosphere, etc. All of these can influence the student's level of motivation in any school subject. 
Thus, when we discuss the motivation to learn a second language, we have to take both contexts into consideration. Our research is based on the assumption that these two contexts have an effect on two general characteristics of the student. One of these characteristics derives from the Cultural Context and includes socially relevant variables. In our original research we labelled this component Integrativeness and focussed attention on the individual being interested in learning the language in order to interact with valued members of the other community and/or to learn more about that community (i.e., an integrative orientation and favourable attitudes toward the community), but in later research we found that it could also involve an open interest in other cultural communities in general (i.e., an absence of Ethnocentrism and authoritarianism, or the presence of Xenophilic attitudes, etc., which we measured with our interest in Foreign Languages scale. Because of the excess meanings that have become associated with the "integrative" concept, I now sometimes refer to it as Openness, or Openness to Cultural Identification. The important point is that Integrativeness reflects the various attributes that can be linked to the Cultural Context of language. Other researchers have identified similar constructs in their studies in different cultural settings (see, for example, Kraemer, 1993; Yashima, 2002)

The other characteristic of the individual that our model considers to be important in second language learning derives from the Educational Context, and includes all variables that can be linked directly to the educational system and the experiences associated with the educational environment. We have labelled this characteristic as Attitudes toward the Learning Situation because it is our assumption that it is the influence of the Educational Context on the individual's attitudes that influence the individual's level of motivation.

Furthermore, the two contexts do not operate in isolation of one another. They coexist in their influence on the student. The cultural context can have an effect on the student's attitudinal reaction to the school environment, and the educational context can play a role (though not a large one, and probably more so for young students) in the individual's level of integrativeness.

As shown in Figure 2, Integrativeness and Attitudes toward the Learning Situation are expected to have an influence on the individual's level of motivation. And, as indicated earlier, motivation is a multifaceted construct. The motivated individual is goal directed, expends effort, is persistent, is attentive, has desires (wants), exhibits positive affect, is aroused, has expectancies, demonstrates self-confidence (self-efficacy), and has reasons (motives). All of these attributes characterize the individual who is motivated to learn a language. In our research, we have found that we can tap into motivation in terms of three measures which tap the cognitive, affective and behavioural components.

Motivation plays a role in various ways in the process of learning a second language. In our research, we have examined a number of them, such as classroom behaviour (Gliksman, Gardner, \& Smythe, 1982), persistence in language study (Clément, Smythe, \& Gardner, 1978), bicultural excursions (Clément, Gardner \& Smythe, 1977), intensive language programs (Gardner, Moorcroft, \& Metford, 1989), language retention (Gardner, Lalonde, Moorcroft \& Evers, 1987), and even modes of acculturation (Young \& Gardner, 1990). In all cases, we have found motivation to account for individual differences. The major point is that motivation plays a role in a number of different ways. 


\section{OUr Results in Spain}

In our research we have focussed attention on six individual difference variables, and have developed measures of them. Two are the constructs of Integrativeness and Attitudes toward the Learning Situation, as discussed above, and another is Motivation (also as discussed above). The other three are Language Anxiety, an Instrumental Orientation, and Parental Encouragement (when testing school age students). These constructs have been a major part of our research. Much of our research has been conducted in Canada with English speaking Canadians learning French and French speaking Canadians learning English, and it has sometimes been claimed that our findings may not apply to other countries or other languages. Five years ago I began a project to determine the applicability of our research to other countries. I now have data concerned with the learning of English as a foreign language in six countries, Spain, Croatia, Poland, Romania, Brazil, and Japan, and last year I presented some of the findings from the European countries at the Eurosla conference in Dubrovnik, Croatia (see, Gardner, 2005). I was amazed at how consistent the findings were, and how similar they were to the Canadian data. Some of the findings for two age samples of students in Barcelona are presented in Table 1.

Table 1: Correlations of Variables with English Grades for Spanish Students

\begin{tabular}{|l|l|l|}
\hline \multicolumn{1}{|c|}{ Variables } & \multicolumn{1}{|c|}{$\begin{array}{c}\text { E.S.O. 2 } \\
\mathrm{N}=166\end{array}$} & \multicolumn{1}{c|}{$\begin{array}{c}\text { E.S.O. 4 } \\
\mathrm{N}=136\end{array}$} \\
\hline Attitude toward Learning Situation & .14 & $.18^{*}$ \\
Integrativeness & $.32 * *$ & $.37 * *$ \\
Language Anxiety & $-.39 * *$ & $-.38^{* *}$ \\
Instrumental Orientation & $22 * *$ & $.21^{* *}$ \\
Parental Encouragement & .12 & .04 \\
Motivation & $40^{* *}$ & $.49 * *$ \\
& & \\
\hline
\end{tabular}

This table presents the correlation coefficients of the six variables with Grades in English for a sample of 166 E.S.O. 2 students and 136 E.S.O. 4 students in Barcelona. Note that the highest correlate is Motivation. Grades in English are more highly related to the measure of motivation in both samples than any of the other variables, indicating that the more highly motivated students have higher grades than the less motivated ones. Note too that the next highest correlate in both samples is the measure of Language Anxiety. In this case, the correlation is negative indicating that the more anxious the student the lower the English grade. The next highest correlation, again in both samples, is Integrativeness, and the correlation is positive. Students with an openness to cultural identification, and/or a favourable attitude and interest in English speaking communities achieve higher grades in English than those who are less willing or less able to take on characteristics of another cultural community. The next highest correlate in both samples is an Instrumental Orientation, and the positive correlation indicates that students who see the instrumental value in learning English do better in English than those who see it as less important, though the correlation is not very high. It will also 
be noted that parental encouragement, as seen by the child is not a significant correlate of English grades.

Probably, the most surprising finding in the table is the relatively low correlation between Attitudes toward the Learning Situation and Grades in English. It is not significant for the E.S.O. 2 students, and barely so for the E.S.O. 4 students. This is surprising because one would expect that in cooperative classes with an experienced and skilled teacher and good teaching materials, etc., that students would have more favourable attitudes toward the situation and thus would learn more English and thus get higher grades. One could hypothesize any number of reasons for this result, but the simple truth is that we obtain similar results in many of our studies, some of which use grades as the measure of language proficiency while some use other indices of achievement as well.

It has been said in the research literature that because of such findings I don't believe that the teaching situation and the teacher are important in second language learning. But, nothing could be further from the truth. I am not a language teacher but I am a teacher, (actually, a professor of statistics and research design), and I am convinced that what I do and the materials I use are important in the training of the students. But, I also know that the student evaluates what I do and what materials I recommend, and that the student's attitudes will influence how he or she reacts to the task at hand. In short, I am convinced that my activities can influence the student's level of motivation, and it is this level of motivation that will have an effect on how much is learned.

Our model of second language acquisition proposes that although many variables can correlate with ultimate achievement in a learning task, the actual effect of these variables on achievement will be mediated by motivation. In order to test this hypothesis with these data, I performed a Path analysis for the two samples separately. The path analysis for the E.S.O. 2 students is shown in Figure 3.

Figure 3: Path Analysis for E.S.O. 2 Students

Path Analysis for E.S.O. 2 Students

(GFI=.985; $\mathrm{CFI}=.994)$

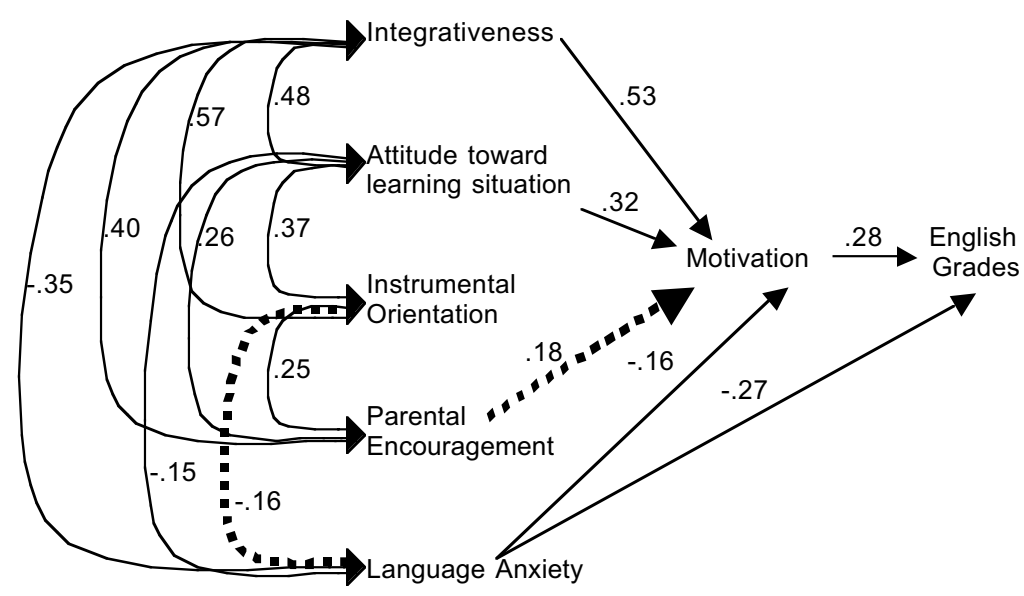


Path analysis is a technique that permits a researcher to test a specific model of the relationship among a series of variables, and results in a diagram indicating the correlations between what are called exogenous variables and regression coefficients linking the endogenous variables with the exogenous variables and other endogenous variables. All of the coefficients shown in the model are significant, and as shown in the title to the path diagram the fit indices (GFI and CFI) are very good, with a value of 1 indicating an excellent fit to the data. The model indicates that Motivation has a positive influence on English Grades while Language Anxiety has a negative influence. It indicates too that Integrativeness, Attitudes toward the Learning Situation, and Parental Encouragement have a positive influence on Motivation while Language Anxiety has a negative influence. Note too that there are substantial correlations among many of the exogenous variables. In particular there are high correlations between Integrativeness, and Attitudes toward the Learning Situation, Instrumental Orientation, and Parental Encouragement, indicating a link between Integrativeness and these other variables. Finally, note that Integrativeness and Attitudes toward the Learning Situation have the greatest influence on Motivation. Taken together, these results highlight the role that both the educational context and the cultural context play in second language acquisition. Both have a direct effect on motivation, which in turn has a direct effect on language achievement.

Figure 4: Path Analysis for E.S.O. 4 Students

\section{Path Analysis for E.S.O. 4 Students (GFI=.959; $\mathrm{CFI}=.960)$}

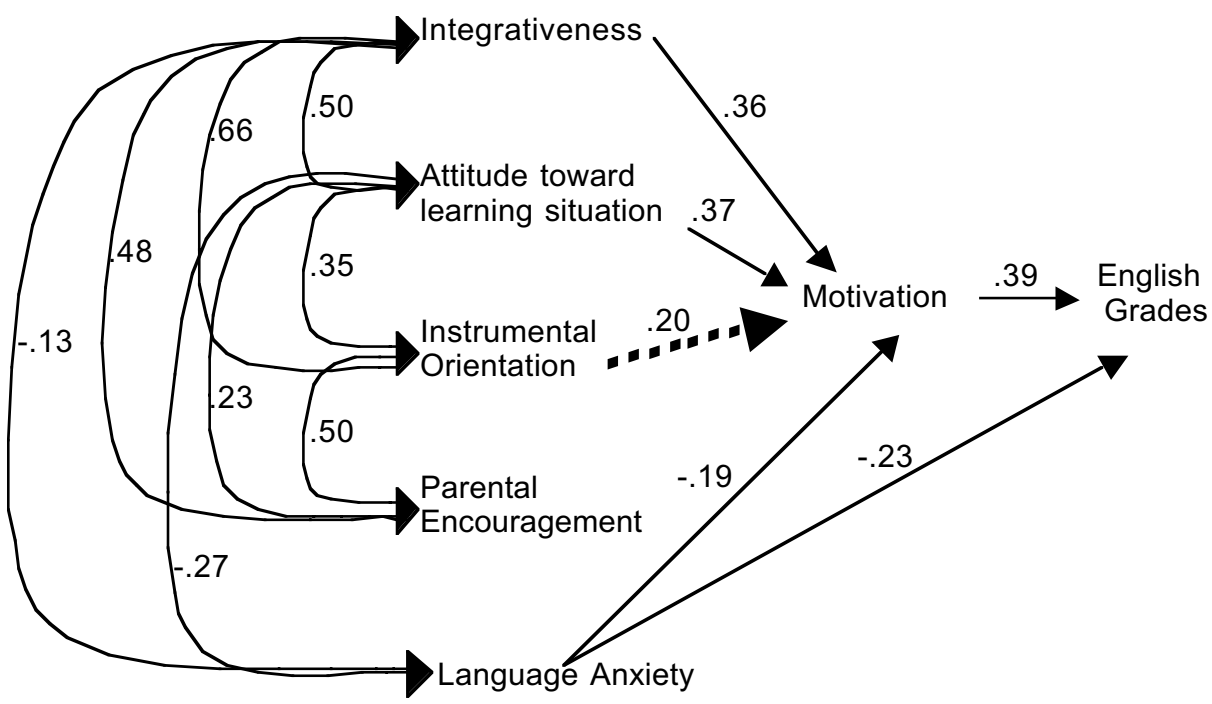


Very similar results were obtained for the E.S.O. 4 students, though there were a few interesting differences, as can be seen in Figure 4. All of the relationships discussed above are also evident with the E.S.O. 4 students. For these students, however, an Instrumental Orientation is shown to have a slight influence on motivation, though this effect was not obtained for the younger students. This would suggest that with age, an instrumental orientation takes on a slightly more important role. Furthermore, note that there is no direct effect of Parental Encouragement on motivation for the E.S.O. 4 students though there was for the E.S.O. 2 students. This would in turn indicate that with age, the perceived influence of the parents is decreased over what it was at an earlier age.

\section{Conclusions}

In our research, we often talk about an integrative motive in second language learning. This was never meant to imply that you needed an integrative motive to learn a second language. When we say that an individual is integratively motivated we mean that:

a. the individual is motivated to learn the other language

b. the individual is learning the language because of a genuine interest in communicating with members of the other language (either because of positive feelings toward that community or members of that community, or because of a general interest in other groups)

c. the individual has a favourable attitude toward the language learning situation.

It is possible to hypothesize other types of motivation, of course, but to me the type of motivation is not that important. In my opinion, the distinction between integrative and instrumental motivation, or between intrinsic and extrinsic motivation does not help to explain the role played by motivation in second language learning. Our research has demonstrated that it is the intensity of the motivation in its broadest sense, incorporating the behavioural, cognitive, and affective components, that is important. Because the Integrative Motive includes the Openness to Cultural Identification (i.e., Integrativeness) as a component it seems likely that it may be more associated with attaining the ultimate level of achievement (i.e., Thought and Automaticity) than other motivational types that lack this component. Classroom learning motivation may promote the acquisition of individual elements of the language, but more is needed to achieve a true mastery of the language. From my perspective the integrative motive serves this need.

\section{REFERENCES}

Clément, R. (1980). "Ethnicity, Contact and Communicative Competence in a Second Language". In H. Giles, W. P. Robinson \& P. M. Smith (eds.), Language: Social Psychological Perspectives. Oxford: Pergamon Press, 147-154.

Clément, R., Gardner, R. C., \& Smythe, P. C. (1977). "Inter-ethnic contact: Attitudinal consequences". Canadian Journal of Behavioural Science, 9: 205-215.

Clément, R., Smythe, P. C., \& Gardner, R. C. (1978). "Persistence in second language study: Motivational considerations". Canadian Modern Language Review, 34: 688-694. 
Dörnyei, Z. (1994). "Motivation and motivating in the foreign language classroom". Modern Language Journal, 78: 273-284.

Dörnyei,Z \& Otto, I. (1998). "Motivation in action: A process model of L2 motivation". Working Papers in Applied Linguistics, 4: 43-69.

Gardner, R. C. (1985a). Social psychology and second language learning: The role of attitudes and motivation. London: Edward Arnold Publishers.

Gliksman, L., Gardner, R. C., \& Smythe, P. C. (1982). "The role of the integrative motive on students' participation in the French classroom". Canadian Modern Language Review, 38: 625-647.

Gardner, R. C., Lalonde, R. N., Moorcroft, R., \& Evers, F. T. (1987). "Second language attrition: The role of motivation and use". Journal of Language and Social Psychology, 6: 29-47.

Gardner, R. C., Moorcroft, R., \& Metford, J. (1989). "Second language learning in an immersion programme: Factors influencing acquisition and retention". Journal of Language and Social Psychology, 8: 287-305.

Heckhausen, H., \& Kuhl, J. (1985). "From wishes to action: The dead ends and short cuts on the long way to action". In M. Frese and J. Sabin (eds.), Goal-directed behavior: The concept of action in psychology, Hillsdale, NJ.: Lawrence Erlbaum.

Kleinginna, P.R. \& Kleinginna, A.M. (1981). "A categorized list of motivational definitions with a suggestion for a consensual definition". Motivation and Emotion, 5: 263-291.

Kraemer, R. (1993). "Social psychological factors related to the study of Arabic among Israeli high school students". Studies in Second Language Acquisition, 15: 83-105.

Krashen, S. D. (1981). Second language acquisition and second language learning. New York: Pergamon.

Lambert, W. E. (1955). "Measurement of the Linguistic Dominance of Bilinguals". Journal of Abnormal and Social Psychology, 50:197-200.

Lambert, W. E. (1956a). "Developmental aspects of second-language acquisition: I. Associational fluency, stimulus provocativeness, and word-order influence". The Journal of Social Psychology, 43: 83-89.

Lambert, W. E. (1956b). "Developmental aspects of second-language acquisition: II Associational Stereotypy, associational form, vocabulary commonness, and pronunciation". The Journal of Social Psychology, 43: 91-98.

Lambert, W. E. (1956c). "Developmental aspects of second-language acquisition: III. A description of developmental changes". The Journal of Social Psychology, 43: 99-104.

MacIntyre, P.D., Clément, R., Dörnyei, Z., \& Noels, K.A. (1998). "Conceptualizing willingness to communicate in a L2: A situated model of confidence and affiliation". Modern Language Journal, 82:545-562.

Noels, K.A., \& Clément, R. (1996). "Communication across cultures: Social determinants and acculturative consequences". Canadian Journal of Behavioural Science, 28:214-228.

Yashima, T. (2002). "Willingness to communicate in a second language: The Japanese EFL Context". The Modern Language Journal, 86:54-56.

Young, M. Y., \& Gardner, R. C. (1990). "Modes of acculturation and second language proficiency". Canadian Journal of Behavioural Science, 22: 59-71. 